\title{
Historical Perspective of the Development of Thrombin Inhibitors
}

\author{
Fritz Markwardt \\ International Institute of Thrombosis and Vascular Diseases, Erfurt-Frienstedt, Germany
}

\section{Key Words}

Thrombin inhibitors · Heparin · Hirudin •

Synthetic inhibitors · Argatroban

\begin{abstract}
Progress in molecular biology has stimulated interest in the structure and function of thrombin. It has improved our understanding of its central role in thrombogenesis and has clarified the molecular events of inhibitor binding. This development has resulted in the production of recombinant hirudins and hirudin analogues. It has also allowed the molecular design of synthetic antithrombins, and encouraged the development of these products for clinical use. All pharmacological aspects speak in favor of the use of direct thrombin inhibitors as antithrombotic agents, especially in the potential indications where thrombin plays a crucial pathogenetic role. If their apparent advantages compared with heparin can be definitely demonstrated, the direct thrombin inhibitors may become the drug of choice for certain indications.
\end{abstract}

Copyright $@ 2002$ S. Karger AG, Base

\section{Introduction}

The clotting enzyme thrombin takes a central position in the blood coagulation system: thrombin catalyzes not only the formation of insoluble fibrin but also activates the clotting factors V, VIII, XIII and protein C, and causes dramatic changes in platelet membrane permeability. Furthermore, it also has direct effects on the vascular endothelium and initiates several nonhemostatic cellular events, such as stimulation of synthesis and release of mediators from the vascular endothelium (fig. 1).

Since the enzymatic activity of thrombin is essential in such bioregulatory events, inhibition of thrombin at blood and vascular sites should be very effective in controlling various pathophysiological states and is vital for the control of thrombogenesis. Therefore, thrombin has become a primary target for the development of antithrombotic agents.

Up to now, pharmacological control of blood coagulation by thrombin inhibition has been possible only with the mammalian glycosaminoglycan heparin. However, its use may cause certain problems. Apart from the necessity of parenteral administration, heparin exerts its inhibitory effect on the clotting enzymes indirectly via a potentiation of the inhibitory function of antithrombin. Therefore, its inhibitory activity depends on the blood level of this plasma protein.

The resulting pharmacological problem has been addressed by the development of thrombin inhibitors different from glycosaminoglycans that block the clotting enzymes directly.

We initially attempted to solve this problem by isolation and pharmacological characterization of inhibitors from blood-sucking animals. These naturally occurring anticoagulants contain specific inhibitors which block either the formation or the effect of thrombin $[1,2]$.

\begin{tabular}{ll}
\hline KARGER & ( ) 2002 S. Karger AG, Basel \\
Fax + 4161306 12 34-8832/02/0329-0015\$18.50/0 \\
$\begin{array}{l}\text { E-Mail karger@karger.ch } \\
\text { www.karger.com }\end{array}$ & $\begin{array}{l}\text { Accessible online at: } \\
\text { www.karger.com/pht }\end{array}$
\end{tabular}

Fritz Markwardt

International Institute of Thrombosis and Vascular Diseases Das Querigfeld 3

D-99192 Erfurt-Frienstedt (Germany)

Tel./Fax +4936208 70678, E-Mail fmarkwardt@t-online.de 


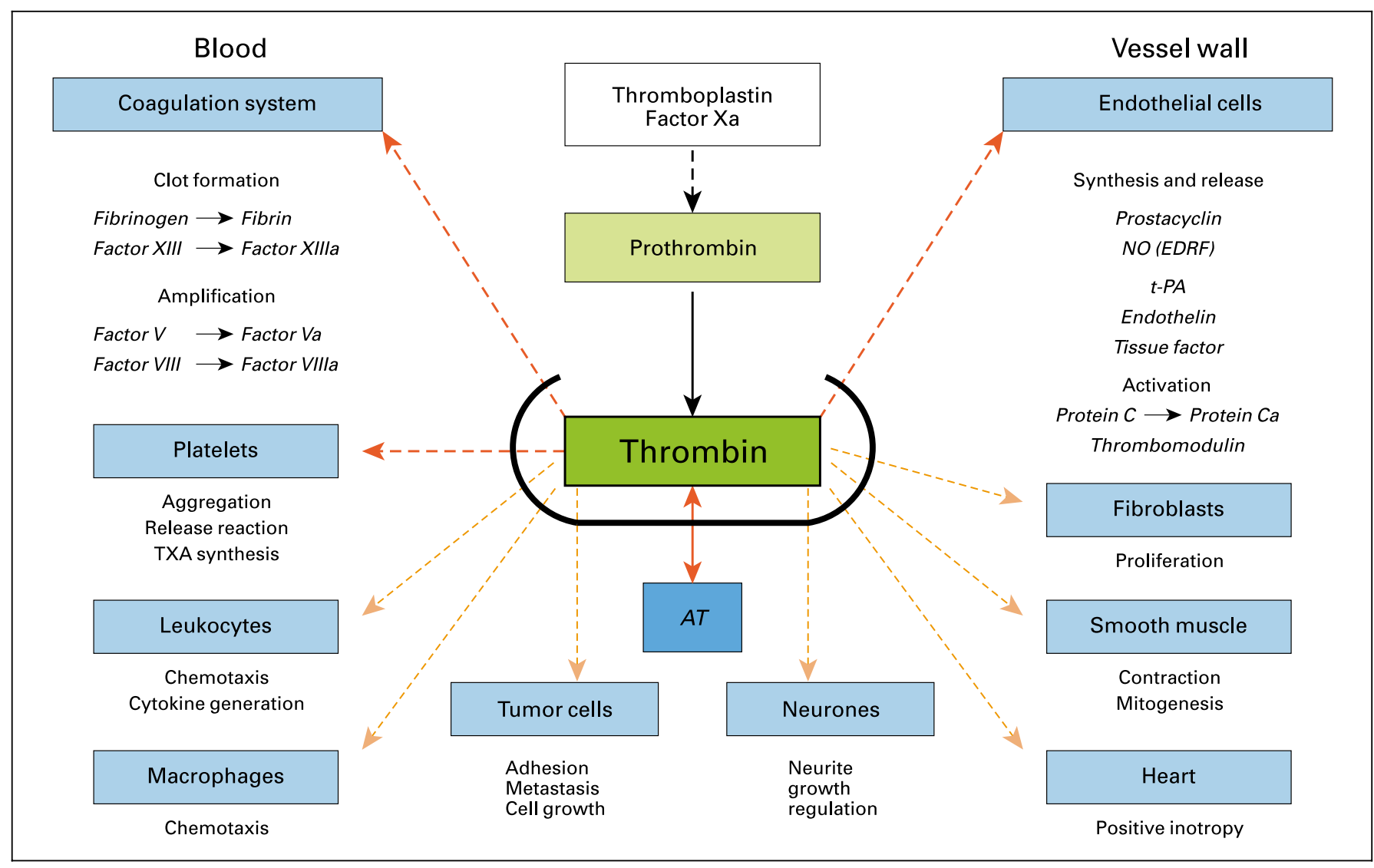

Fig. 1. Inhibition of hemostatic and nonhemostatic effects of thrombin by direct thrombin inhibitors (---).

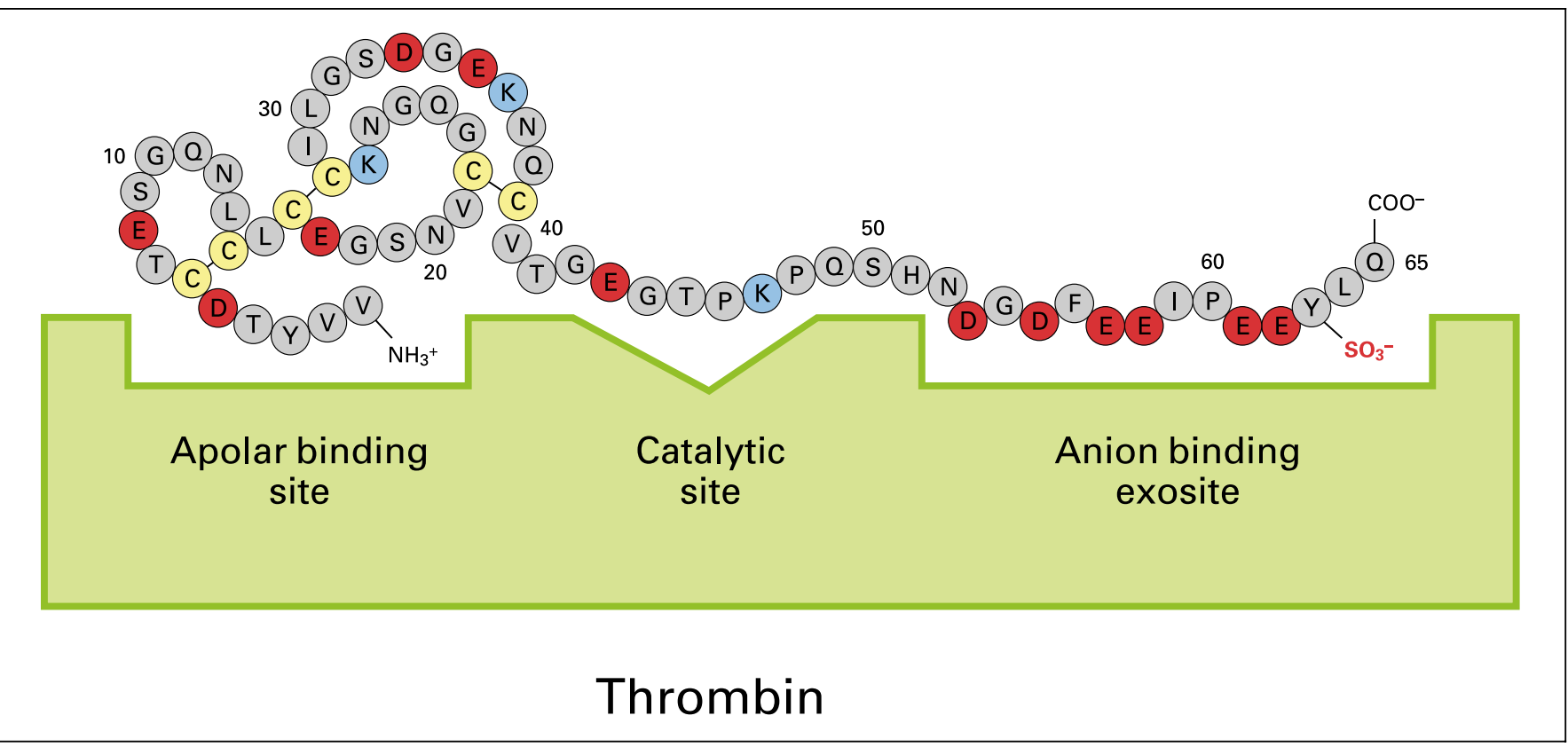

Fig. 2. Primary structure of native hirudin (variant 1, HV1) (amino acids are shown with the single letter code) and schematic representation of the hirudin-thrombin reaction. 
Table 1. Synopsis of thrombin inhibitors

\begin{tabular}{ll}
\hline Characteristics & Chemical nature (type) \\
\hline Hirudin and other specific inhibitors from hematophages & $\begin{array}{l}\text { Natural and recombinant miniproteins } \\
\text { (desirudin, lepirudin) }\end{array}$ \\
\hline Chimeric inhibitors, analogues to hirudin & Synthetic bifunctional oligopeptides (hirulog) \\
\hline Substrate-derived competitive inhibitors & $\begin{array}{l}\text { Peptid arginals and derivatives } \\
\text { (efegatran, inogatran, melagatran) }\end{array}$ \\
\hline Mechanism-based inhibitors, heterocyclic compounds & Peptidomimetics (argatroban, napsagatran) \\
\hline
\end{tabular}

Isolation and sequencing of the inhibitors allowed molecular cloning of the corresponding cDNA, and synthetic genes coding for the inhibitors could be expressed in Escherichia coli or yeast. Therefore, most of the inhibitors have undergone genetic engineering and are now available as recombinant peptides in adequate amounts for experimental and clinical pharmacological studies $[3,4]$.

The specific thrombin inhibitor produced by the medicinal leech (Hirudo medicinalis), named hirudin, was isolated and characterized as a specific high-affinity thrombin inhibitor in the late 1950s. It is a potent specific inhibitor of thrombin and has served as a standard for designing new inhibitors [5-7].

\section{Recombinant Hirudin}

As a consequence of biotechnological production methods, recombinant products allowed the introduction of the most potent natural inhibitor of thrombin as a clinical anticoagulant. Several structural variants of hirudin were produced by recombinant DNA technologies including point mutations and $\mathrm{N}$-terminal modifications (desirudin, lepirudin). This process led to new insights into structure-activity relationships of this unique and promising thrombin inhibitor [8-13].

Hirudin has an unusual asymmetry of structural elements. A compact, hydrophobic core region in the aminoterminal half of the molecule contains alternating polar and nonpolar segments and all three disulfide bonds. The carboxy-terminal region is more extended and extremely hydrophilic.

The crystallographic structure of the hirudin-thrombin complex shows the structural regions of the enzyme and the inhibitor involved in the thrombin-hirudin interaction. It confirms the high affinity of hirudin for thrombin and the specificity of the tight and essentially irreversible binding of hirudin to thrombin (fig. 2).

Development of Thrombin Inhibitors

\section{Synthetic Thrombin Inhibitors}

The limitations of antithrombotic therapy with heparin and analogues and the lessons learned from the clinical use of hirudin have a great impact on the development of synthetic low molecular antithrombin agents as anticoagulant and potential antithrombotic drugs [14].

Through the mid 1970s, several laboratories synthesized large numbers of thrombin inhibitors. The major milestone in this field was the breakthrough achieved in determining the crystal structure of thrombin. The availability of this structure together with the elucidation of structural features of hirudin provides a rational basis for the design and synthesis of peptide and nonpeptide thrombin inhibitors [15-18].

Only a few compounds among the numerous synthetic thrombin inhibitors described have proved to be suitable as anticoagulants. Table 1 presents a synopsis of these inhibitors.

\section{Oligopeptides}

A series of synthetic bifunctional oligopeptides has been modeled according to the natural peptide. Coupling of peptides that mimic the carboxy terminal of hirudin to peptides that are specific for inhibition of the catalytic site of thrombin ( $D$-Phe-Pro-Arg) has led to the development of a series of chimeric molecules termed hirulogs, in which the exosite recognition sequence of the hirudin Cterminus is linked by glycyl residues to a potent ligand directed at the catalytic site (hirulog) [19].

\section{Peptide Arginals and Derivatives}

The development of synthetic thrombin inhibitors is a new example of designing protease inhibitors through the mimicry of substrates. Imitating the amino sequence around the thrombin-scissible bond in fibrinogen, inhibi-

Pathophysiol Haemost Thromb

2002;32(suppl 3):15-22 
Fig. 3. Schematic representation of the reaction of thrombin with direct inhibitors. The catalytic site $(\mathrm{C})$, the anion-binding exosite (B), and the apolar region (A) are the three functional domains of the thrombin molecule that interact with direct thrombin inhibitors. The active site $\mathrm{C}$ contains the catalytic triad (serine/histidine/aspartic acid). It forms a specific pocket that binds the basic arginine and lysine residues of site-directed thrombin inhibitors. The anion-binding exosite (B) (also known as substrate recognition site) is located in a region of the thrombin molecule distant from the catalytic site. It is comprised of multiple basic amino acids that permit it to form ionic bonds with the carboxyl terminus of some natural thrombin inhibitors. The apolar region (A) bonds via hydrophobic interactions with the aminoterminals of natural thrombin inhibitors as well as with hydrophilic groups of synthetic inhibitors.

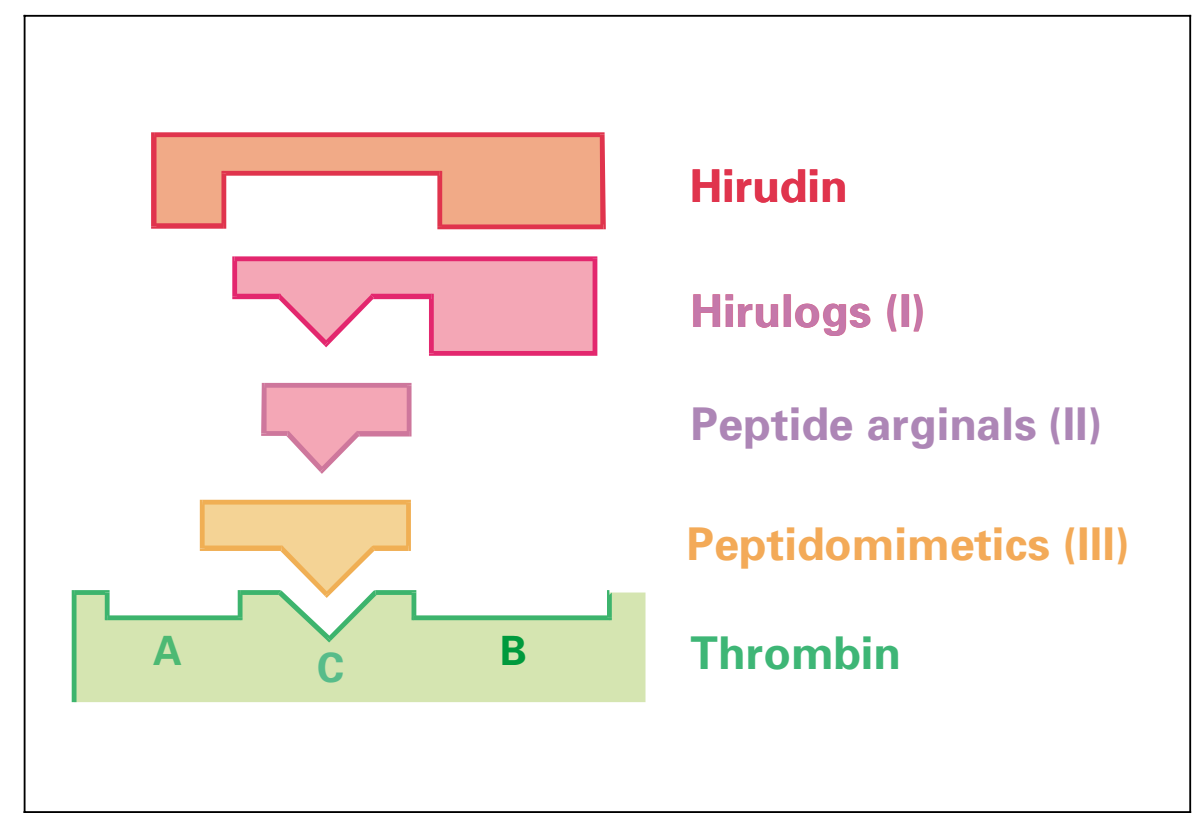

tors were produced that enter into a covalent or non-covalent bond with the active site of the enzyme.

The most useful skeleton in designing active-sitedirected thrombin inhibitors was the sequence Phe-ProArg- $\mathrm{H}$, especially if phenylalanine is in the $D$-configuration [20]. A series of derivatives of the prototype tripeptide aldehyde has been developed as reversible thrombin inhibitors ( $D$-MePhe-Pro-Arg-H, efegatran; $\mathrm{HOOCCH}_{2}-$ $D$-Cha-Pip-Nag, inogatran; $\mathrm{HOOCCH}_{2}$-D-Chg-Aze-Pab, melagatran).

Furthermore, the highly selective affinity label for thrombin, $D$-Phe-Pro-Arg- $\mathrm{CH}_{2} \mathrm{Cl}$ (PPACK), is effective as a covalently binding irreversible thrombin inhibitor. By substitution of the sequence with other reactive groups (for example boronic acid, Ac- $D$-Phe-Pro-boroArg) additional thrombin inhibitors were obtained.

\section{Peptidomimetics}

Modification of substrates is a common principle for designing inhibitors. One of the building blocks used to develop synthetic inhibitors is arginine with optimal Cand/or N-terminal modifications.

Starting from the synthetic thrombin substrate $\mathrm{N} \alpha-$ tosyl- $L$-arginine methyl ester (TAME), Okamoto and his group have designed competitive inhibitors of considerable potency and selectivity by variation of the carbonyl and $\mathrm{Na}$-substituents [21, 22]. Tmq-Arg- $D$-Pip(4-Me)-OH, argatroban, one of the representatives of the peptidomi- metic thrombin inhibitors, has reached the stage of advanced clinical trials and is now available for treatment.

Our group focused on derivatives of benzamidine, which are isosteric to arginine amides and are able to mimic the protonated basic guanidinoalkyl side chain of arginine. Thus we found pseudopeptides possessing structures similar to peptidyl inhibitors ( $\beta$ Nas-Gly- $D$-(4Am)Phe-Ppd, NAPAP) [23, 24].

An alternative building block used to develop small inhibitors for the catalytic site of thrombin is amidinopiperidine. Modifications of this molecule yielded competitive inhibitors for thrombin ( $\beta$ Nas-Asp(O-NPG)Phe-Ppd, napsagatran).

In order to evaluate the potential usefulness of the direct thrombin inhibitor for therapeutic purposes, a special program of in vitro and in vivo investigations was established [25-28].

\section{Anticoagulant Action}

The anticoagulant action of the inhibitors is one of the first biological effects to be tested after biochemical studies on their enzyme inhibitory activity. A scheme of their mode of action is shown in figure 3.

By instantaneous inhibition of the small amount of thrombin generated after activation of the clotting system, the positive feedback on prothrombin activation that would normally lead to accelerated generation of thrombin - is prevented and thrombin generation is 
delayed. Thus, depending on the inhibitor concentration in blood, coagulation is retarded or completely inhibited.

Moreover, thrombin inhibitors not only prevent thrombin-catalyzed hemostatic reactions including the thrombin-induced platelet aggregation and release reaction, but also the synthesis and release of some mediators from the vascular endothelium and the binding of thrombin to endothelial thrombomodulin. In addition, they will interfere with all the humoral effects of thrombin, such as proliferation of fibroblasts and contraction and mitogenesis of smooth muscle cells. In particular, the vasoconstrictor action of thrombin in deendothelialized vessels may be inhibited. Thus, the specific thrombin inhibitors may interfere with essential vascular mechanisms of thrombosis (fig. 1).

\section{Antithrombotic Effects}

The efficacy of thrombin inhibitors in preventing venous and arterial thrombosis was demonstrated in various animal models in which the pathological mechanism largely corresponded to those of thromboembolic disorders in man. The anti-thrombotic effect was confirmed by prevention of thrombi induced in the venous stasis model. It was demonstrated in arterial thrombosis induced by vessel wall lesions. Reocclusion after experimental thrombolysis and angioplasty was also inhibited. The prevention of microthrombosis was repeatedly demonstrated in disseminated intravascular coagulation. The efficiency in preventing clot formation on artificial surfaces was quantified by experiments in which materials of varying thrombogenicity were placed in an extracorporeal circuit $[26,27]$.

Even if the clinical relevance of thrombosis models in experimental animals remains debatable, the antithrombotic effectiveness of the direct thrombin inhibitors has been clearly demonstrated. In general, their outstanding efficacy became obvious when thrombin was initially formed by diffuse intrinsic or extrinsic activation of the coagulation pathway. Stasis-induced venous thrombosis and disseminated microthrombosis were most sensitive. Comparatively higher doses were required in arterial thrombosis and extracorporeal shunt thrombosis, in which platelets play a role. These differences may be explained by the finding that the inhibition of the thrombin-platelet reaction requires higher inhibitor concentrations than that of the thrombin-fibrinogen reaction.

Clinico-pharmacologic studies corroborated the specific pharmacological properties of the site-directed antithrombin agents such as hirudin, oligopeptides, synthetic tripeptides derivatives and peptidomimetics found in ani- mal experiments. The new thrombin inhibitors are currently undergoing various phases of clinical trials. Moreover, for a broader clinical application of thrombin inhibitors as antithrombotics the following issues warrant consideration.

\section{Pharmacokinetics}

Thrombin inhibitors do not find a preformed, permanent systemic target in the organism. Instead, their specific binding site is present only when the target enzyme is generated. Therefore, the effect of thrombin inhibitors in vivo depends on their pharmacokinetic behavior, especially the time course of their blood levels.

The pharmacokinetic behavior of hirudin can best be described by an open two-compartment model with firstorder kinetics. Following an intravenous bolus injection, hirudin is distributed into the extracellular space and predominantly excreted in the urine with a half-life of $60 \mathrm{~min}$. After subcutaneous administration, peak plasma levels were reached after $1-2 \mathrm{~h}$ and bioavailability was calculated as $70-80 \%$. There is some absorption of hirudin after intratracheal instillation. Rectal or intraduodenal and percutaneous administration did not lead to detectable plasma levels [29].

The percentage of the dose that was renally excreted in unmodified form differed in various species. The activity lasted longer in anephric animals, suggesting that the kidney is a major route of elimination. Accordingly, hirudin elimination from blood can be retarded by coupling to biomacromolecules, such as dextran or polyethylene glycol [30-32].

The short biological half-life of synthetic thrombin inhibitors, ranging from 10 to $60 \mathrm{~min}$, represents a limitation for their broader clinical application. Poor mucous membrane permeation and/or extensive hepatic first pass effect is probably the reason for the lack of activity after oral administration of these inhibitors, which have to be classified as parenteral thrombin inhibitors.

There is a need for an orally applicable formulation of a synthetic thrombin inhibitor that achieves a prolonged inhibition of thrombin. The aim to find substances which are active when administered orally is a goal to be achieved for this new class of drugs and will become an active field of pharmacological research in the future.

\section{Hemostasis}

One of the drawbacks of anticoagulants is that hemostasis is impaired and thus entails a risk of bleeding. But therapeutic doses of thrombin inhibitors were tolerated without adverse effects, in particular bleeding tendencies, 
Table 2. Comparison of pharmacological properties of antithrombin agents

\begin{tabular}{lll}
\hline Heparin & Hirudin & Synthetic inhibitors \\
\hline Family of sulfated glycosaminoglycans & Single-chain polypeptide & Peptides or peptidomimetics \\
\hline $\begin{array}{l}\text { Isolation and purification procedures } \\
\begin{array}{l}\text { Multiple sites of action, potentiate inactivation } \\
\text { of clotting enzymes by plasma inhibitors }\end{array}\end{array}$ & $\begin{array}{l}\text { Selective, tight binding inhibitor acts by } \\
\text { inhibiting thrombin-mediated coagulation }\end{array}$ & $\begin{array}{l}\text { Specific, direct inhibitors acting by } \\
\text { competitive inhibition of the clotting } \\
\text { enzyme }\end{array}$ \\
\hline $\begin{array}{l}\text { Requires endogenous cofactors (ATII) } \\
\begin{array}{l}\text { Interaction with endothelium and plasma } \\
\text { proteins }\end{array}\end{array}$ & Does not require cofactors & Does not require cofactors \\
\hline $\begin{array}{l}\text { Direct or immune-mediated platelet activation } \\
\text { No activity against clot-bound thrombin }\end{array}$ & No direct effects on platelets & Limited effect on blood constituents \\
\hline $\begin{array}{l}\text { Neutralized by antiheparins, metabolized in } \\
\text { liver degradation }\end{array}$ & Limited activity against clot-bound thrombin & Inhibits clot-bound thrombin \\
\hline
\end{tabular}

Further prospects

Low molecular weight heparin fractions and

unless administered at doses considerably higher than required for antithrombotic efficiency [33].

Nevertheless, it is desirable to have antidotes available against any unexpected bleeding, i.e. an antagonist. In contrast to heparin, which could be neutralized by protamine, no specific antidote against thrombin inhibitors can be recommended at present. However, as revealed by our experimental studies, several possibilities exist. Prohemostatic agents, such as prothrombin complex concentrates, could antagonize the anticoagulant effects. They furnish thrombin, which forms an inactive complex with the thrombin inhibitor. Furthermore, chemical and genetically modified thrombin and meizothrombin, that are not prothrombotic but still bind to thrombin inhibitors, neutralize the antithrombotic agents. However, these antidotes still need careful preclinical and clinical evaluation.

\section{Special Indications}

A comparison of the pharmacological characteristics of the antithrombin agents illustrates the progress and problems in the development of direct thrombin inhibitors (table 2).

Short peptides or peptide analogues have the advantage of being less expensive to prepare. They have the potential to be orally active. In contrast to hirudin and its analogues, synthetic inhibitors have lower specificity, possess side chains or reactive groups, which can react with various plasma components producing side effects and leading to relatively rapid loss of activity in blood, besides their hepatic metabolism.

Direct thrombin inhibitors, either the naturally occurring or recombinant and the synthetic ones, are novel antithrombotic agents in a field where heparin has been the only available drug so far [34].

Compared with heparin, thrombin inhibitors possess a number of advantages since they do not require the presence of endogenous cofactors like antithrombin III. Hence patients with deficiencies in this protein, as is the case in disseminated intravascular coagulation, can be treated with direct thrombin inhibitors.

Furthermore, thrombin inhibitors are not bound or inactivated by platelet factors or other proteins acting as antiheparin substances. They have no influence on platelet function and no direct or immune-mediated plateletactivating properties. Therefore, they should be advantageous under conditions in which platelet defects or heparin-induced thrombocytopenia may present a risk.

For the effect in thrombosis it is of interest that the inhibitors - in contrast to the heparin-antithrombin complex - are able to block thrombin bound to the fibrin network, whereby the growth of preexistent thrombi can be 
prevented and thrombin which might be released during endogenous thrombolysis was inhibited. Therefore, thrombin inhibitors may be suited as a postoperative prophylactic agent.

The central role of thrombosis in the pathogenesis of acute myocardial infarction, unstable angina, and complications after angioplasty (especially reocclusion) has led to intense interest in developing antithrombin agents for the management of coronary ischemic syndromes. Thrombin inhibitors also were used in the management of extracorporeal circulation and hemodialysis.

The pathophysiological role of thrombin, extending beyond coagulation and platelet activation, suggests that thrombin inhibitors could equally be used as therapeutic tools in areas other than blood coagulation. Indeed, effects of thrombin on other cell types and function, ranging from mitogenesis and contraction of smooth muscle cells to adhesion and metastasis of tumor cells, were inhibited. Although the functions of thrombin in such processes have not been fully characterized, areas covered by antithrombin drugs could include acute inflammatory response, tissue repair, and modulation of cellular viability.

\section{Conclusion}

The production of naturally occurring and synthetic thrombin inhibitors has encouraged the development of these products as antithrombotic agents. All pharmacological aspects speak in favor of the clinical use of direct antithrombins especially in potential indications where thrombin plays a crucial role in the pathogenesis.

Demonstration of their ultimate clinical utility and advantages, however, represents a substantial challenge and has led to fundamental questions:

- Will thrombin inhibitors be substitutes, supplements, or successors to heparin?

- Which clotting assay can best predict the antithrombotic effect?

- What is the therapeutic window in different clinical settings?

Moreover, considering the multiple functions of thrombin, it remains to be clarified whether thrombin inhibitors might also have other indications than prevention of acute thrombotic events.

\section{References}

1 Markwardt F: Blutgerinnungshemmende Wirkstoffe aus blutsaugenden Tieren. Jena, Gustav Fischer, 1963.

2 Markwardt F, Landmann H: Blutgerinnungshemmende Proteine, Peptide und Aminosäurederivate; in Markwardt F (ed): Handbuch der experimentellen Pharmakologie. Berlin, Springer, 1971, vol 27: Anticoagulantien, pp 76-142.

3 Markwardt F: Coagulation inhibitors of bloodsucking animals - A new line of developing antithrombotic drugs. Pharmazie 1993;49: 313-316.

4 Markwardt F: Antithrombotic agents from hematophagous animals. Clin Appl Thromb Hemost 1996;2:75-82.

5 Markwardt F: Isolierung und chemische Charakterisierung des Hirudins. Hoppe Seylers Z Physiol Chem 1957;308:147-156.

6 Markwardt F, Walsmann: Reindarstellung und Analyse des Thrombin-Inhibitors Hirudin. Hoppe Seylers Z Physiol Chem 1967;348: 1381-1386.

7 Markwardt F: Hirudin as an inhibitor of thrombin; in Colowick SP, Kaplan NO (eds): Methods in Enzymology. New York, Academic Press, 1970, vol 19: Proteolytic Enzymes, pp 924-932.
8 Markwardt F, Fink E, Kaiser B, Klöcking HP, Nowack G, Richter M, Stürzebecher J: Pharmacological survey of recombinant hirudin. Pharmazie 1988;43:202-207.

9 Markwardt F: Development of hirudin as an antithrombotic agent. Semin Thromb Hemost 1989; 15:269-282.

10 Markwardt F: Hirudin and derivatives as anticoagulant agents. Thromb Haemost 1991;66: 141-152.

11 Markwardt F: Past, present and future of hirudin. Haemostasis 1991;21(suppl1):11-26.

12 Markwardt F: Le génie génétique conduit au retour de l'hirudine comme anticoagulant. Sang Thrombos Vaisseaux 1991;3:519-522.

13 Markwardt F: The development of hirudin as an antithrombotic drug. Thromb Res 1994;74: $1-23$.

14 Markwardt F: Synthetic, low molecular thrombin inhibitors. A new concept of anticoagulants? Haemostasis 1974; 3:185-202.

15 Markwardt F: Pharmacological control of hyperproteolytic states in blood by synthetic inhibitors of serine proteinases. Haemostasis 1978:7:177-182.

16 Markwardt F: Pharmacological control of blood coagulation by synthetic low-molecularweight inhibitors of clotting enzymes. A new concept of anticoagulants. Trends Pharmacol Sci 1980;1:153-157.
17 Hauptmann J, Markwardt F: Pharmacological aspects of the development of selective synthetic thrombin inhibitors as anticoagulants. Semin Thromb Hemost 1992;18:200-217.

18 Hauptmann J, Stürzebecher J: Synthetic inhibitors of thrombin and factor Xa: From bench to bedside. Thromb Res 1999;93:203-241.

19 Marganore JM, Bourdon P, Jablonski J, Ramachandran KJ: Design and characterization of hirulogs, A novel class of bivalent peptide inhibitors of thrombin. Biochemistry 1998;29: 7095-7101.

20 Bajusz S, Szeli E, Bagdy D, Barabas E, Horvath G, Diosszegi M, Szabo G, Juhasz A, Tomori E, Szilagy G: Highly active and selective anticoagulants: $D$-Phe-Pro-Arg-H, a free tripeptide aldehyde prone to spontaneous inactivation, and its stable M-methyl derivative, $D$-MePhe-ProArgH. J Med Chem 1990;33:1729-1735.

21 Okamoto S, Kinjo K, Hijikata A: Thrombin inhibitors. 1. Ester derivatives of $\mathrm{N} \alpha$-(arylsulfonyl)-arginine. J Med Chem 1980;23:827-830.

22 Matsuo T, Kario K, Kodama K, Okamoto S: Clinical applications of the synthetic thrombin inhibitor, argatroban (MD 805). Semin Thromb Hemost 1992;18:216-218.

23 Stürzebecher J, Markwardt F, Voigt B, Wagner G, Walsmann P: Cyclic amides of $\mathrm{Na}$-arylsulfonylaminoacylated 4- amidinophenylalanin tight binding inhibitors of thrombin. Thromb Res 1983;29:635-642. 
24 Kaiser B. Hauptmann J, Weiss A, Markwardt F: Pharmacological characterisation of a new highly effective synthetic thrombin inhibitor. Biomed Biochim Acta 1985;44:1201-1210.

25 Markwardt F, Hauptmann J, Nowak G, Klessen C, Walsmann P: Pharmacological studies on the antithrombotic action of hirudin in experimental animals. Thromb Haemost 1982; 47:226-229.

26 Markwardt F, Kaiser B, Nowak G: Studies on antithrombotic effects of recombinant hirudin. Thromb Res 1989;54:377-388.

27 Markwardt F, Klöcking HP: Antithrombotic effect of synthetic thrombin inhibitors. Thromb Res 1972;1:243-252.
28 Markwardt, F: Pharmacology of selective thrombin inhibitors. Nouv Rev Fr Hématol 1988;30:161-165.

29 Markwardt F, Nowak G, Stürzebecher J: Clinical pharmacology of recombinant hirudin. Haemostasis 1991;21:133-136.

30 Richter M, Walsmann P, Markwardt F: Plasma level of dextran-r-hirudin. Pharmazie 1989;44: 73.

31 Markwardt F, Richter M, Walsmann P, Riesener G. Paintz M: Preparation of dextranbound recombinant hirudin and its pharmacokinetic behavior. Biomed Biochim Acta 1990; 49:1103-1126.
32 Rübsamen K, Hornberger W, Schweden J, Kurfürst M: Pharmacological characterization of a long acting polyethylen glycol-coupled recombinant hirudin. Thromb Haemost 1991; 65:1291.

33 Kaiser B, Markwardt F: Antithrombotic and haemorrhagic effects of synthetic and naturally occurring thrombin inhibitors. Thromb Res 1986;43:613-620.

34 Markwardt F: Development of direct thrombin inhibitors in comparison to glycosaminoglycans. Semin Thromb Hemost 2001;27:523530. 